Linha D'Água (Online), São Paulo, v. 31 , n. 1, p. 9-27, jan.-abril 2018

\title{
OS MEANDROS DA ESCRITA ACADÉMICA. ALGUNS RECADOS AOS ESTUDANTES UNIVERSITÁRIOS
}

\author{
THE MEANDERS OF ACADEMIC WRITING. SOME TIPS TO \\ UNDERGRADUATES
}

\author{
Maria da Graça Lisboa Castro Pinto* \\ Universidade do Porto, Porto, Portugal
}

\begin{abstract}
Resumo: A escrita-composição é uma atividade que requer uma prótica continuada, não se reduzindo, por isso, a uma mera mecânica que mais não exige do que justapor palavras, exerćcicio que, na melhor das hipóteses, obedece às regras prescritas pela gramática. As novas tecnologias da comunicação, tão usadas na atualidade, nem sempre tornam visiveis bons exemplares de escrita, o que alerta imediatamente para a realidade nua e crua que deriva dessa vivência. Não bastam os meios. Apesar de as mensagens se subordinarem a esses meios, importa fazer sentir, nomeadamente aos jovens, que existem vários registos de escrita e que na Universidade deles vai ser reivindicada uma escrita - a académica - que tem de respeitar tanto uma redaç̃ó caracterizada por regras espećficas, como uma estrutura regida por normas próprias, estabelecidas internacionalmente. É objetivo deste texto deixar alguns recados aos estudantes que se iniciam na escrita académica para que venham a redigir trabalhos que se aproximem do que deles espera a comunidade cientifica que os há de avaliar e que eles seguramente quererão vir a integrar.
\end{abstract}

Palavras-chave: TIC; Meio e mensagem; Escrita; Diferentes registos; Trabalhos académicos e suas exigências.

\begin{abstract}
Writing-composition requires an ongoing practice that entails more than the mere mechanics of juxtaposing words that, at its best, goes no further than obeying the rules prescribed by grammar. The new technologies of communication, so much used nowadays, don't always provide good written samples which could be an alert to the sober reality that arises from this context. Means are therefore not enough. Eventhough messages are dependent on those means, it is important to allow young students to experience different language registers since university will claim a kind of writing - academic - which should respect both specific rules and a kind of structure conditioned by its own internationally established norms. This text aims at giving some hints to students who are new to academic writing in hopes this will enable their future texts to come closer to what the scientific community expects, given that this is the same community which will evaluate them and that students themselves will surely want to integrate.
\end{abstract}

Keywords: ICT; Means and Message; Writing; Different Language Registers; Academic Papers' Requirements.

* Professora Catedrática da Universidade do Porto - UP, Porto, Portugal; mgraca@letras.up.pt 
Linha D'Água (Online), São Paulo, v. 31, n. 1, p. 9-27, jan.-abril 2018

\section{Introdução}

Tornou-se já um lugar-comum (ouvir) dizer que nunca se escreveu tanto como presentemente. De facto, a escrita nunca terá sido colocada de uma maneira tão significativa ao serviço da comunicação por força das novas tecnologias da informação e da comunicação, que hoje conhecem uma popularidade incontestável.

Estes novos meios de informação e de comunicação, em constante atualização a uma velocidade indomável, atraem de tal forma a população em geral que só poucos não se mostram minimamente incomodados com a possibilidade de virem a sentir-se excluídos desse mundo ou de serem, em consequência dessa opção de vida, incapazes de competir com os seus pares.

A despeito de se verificar que a escrita se converteu atualmente numa prática mais comum, não se pode inferir que dessa constatação transcorra que escrever muito é sinónimo de redigir com correção. Se esses novos meios de comunicação eletrónicos estão associados a um domínio de literacia digital compatível com o seu uso em níveis aceitáveis, não se poderá dizer que quem deles se vale, não sem um grau exagerado de dependência em muitos casos, possui inevitavelmente um domínio da escrita que o capacite a dela oferecer bons exemplares de composição. Fez-se só alusão ao uso quando se referiu à literacia digital. Interessa, todavia, ter presente que a literacia digital não se restringe unicamente a essa aceção; ela também contempla outra aceção mais exigente associada à capacidade de programação. Esta última visão da literacia digital não é, contudo, apanágio de todos os que se movem nesses meios.

A disparidade entre o aparente à vontade que se constata na forma como certas pessoas utilizam essas novas tecnologias e a pouca qualidade que se pode observar nas suas produções escritas constitui certamente um cenário que é tudo menos estranho a quem tem por ofício ensinar, independentemente do nível em que atua.

A questão que se pode deixar no ar é se essa falta de desenvoltura na composição se deve só aos alunos ou mesmo aos estudantes, quando se trata de níveis de ensino superiores, ou se, como nota Odell (1980: 139), "[s]tudents do not write well because they are not taught to write". A frase de Odell talvez faça ainda mais sentido em etapas mais avançadas de ensino porque se pressupõe que tudo o que tinha a ver com a escrita já foi ou já devia ter sido ensinado até então. 
Linha D'Água (Online), São Paulo, v. 31, n. 1, p. 9-27, jan.-abril 2018

A escrita pode, é bem certo, ensinar-se, mas ela vive também muito do que nela cada um puser em matéria de prática. Ninguém espere, contudo, que o resultado final que se almeja não implica esforço e tempo. É que o caminho pode ser longo e sinuoso, dependendo das imposições da tarefa e da fase em que se encontrar o seu desenho. Donald Murray (2013) documenta bem o exposto com as seguintes frases: "Writing is not a mystery. It is a craft, a habit, a discipline that can be understood and practiced." (p. 24), “- the writing comes in the writing -" (p. 28), "Writing produces writing." (p. 30).

A escrita não é, porém, passível de se desvincular da leitura. Não é suficiente assinalar, como argumenta Murray (2013, p. 43), que a escrita é um ato de ler, porquanto lemos à medida que vamos escrevendo. A escrita apoia-se, com efeito, na leitura e ela será tanto mais enriquecida por esta quanto mais informação for necessária para sustentar o que se vai redigindo. A necessidade de informação decorrente de uma investigação rigorosa ainda é mais compreensível quando se trata da escrita académica, que é, aliás, a eleita para tema do presente texto. A escrita não conta somente com o seu autor como leitor, naturalmente o primeiro, ela tem também de ser pensada para o público leitor a quem se dirige. Vista nesta ótica, uma escrita escorada numa informação bem fundamentada, porque estribada em leituras advenientes de uma investigação séria, terá por certo um público assegurado e poderá, sem dificuldade, contribuir para que se sinta que o agente da escrita também reveste uma faceta de investigador. No trabalho académico, essa ligação não pode deixar de ocorrer. Só se pode concordar com D. Murray quando, para justificar que o papel de escritor coincide com o de investigador, escreve: "Writers don't write with words. Writers write with information: accurate, specific, significant information produced by effective research.” (MURRAY, 2013, p. 133). Conforme prossegue, não são unicamente os cientistas que são investigadores. A mensagem que emana da citação transcrita deve ser bem apreendida pelos estudantes para que as suas produções escritas venham a ter a receção desejada junto da comunidade científica a que projetam pertencer.

Deve ficar claro que um trabalho académico, porque de cunho científico, poderá, tomando de empréstimo expressões de Skelton (1997), prescindir da "verdade baseada em provas", quando não possuir uma parte empírica, mas terá de comportar 
Linha D'Água (Online), São Paulo, v. 31, n. 1, p. 9-27, jan.-abril 2018

sempre uma "verdade interpretada", firmada numa "verdade contextualizada" advinda da investigação teórica de que qualquer trabalho científico não dispensa.

Esta introdução não pode ser finalizada sem que se refira a existência de diferentes registos de escrita, quer em consonância com os objetivos consignados no estudo a realizar, quer em resultado da influência que o meio utilizado exerce sobre a mensagem, posto que foi chamada a terreiro a comunicação mediada por computador. Justifica-se, assim, a evocação da célebre frase de Mac Luhan: "A mensagem é o meio". Por obra do meio que gera um novo ambiente, a adaptação passa então a verificar-se com implicações tanto na mensagem, como na forma de pensar e de sentir (BALLE, 1972).

Recorrendo a Crystal (2001), cabe ainda sublinhar como, em matéria de escrita, os novos tipos de linguagem informal, a par da formal, concorrerão para uma maior diversidade linguística e para que se crie em quem deles se vale uma maior sensibilidade para contrastes linguísticos de toda a ordem. Esta nota de otimismo constitui igualmente um alerta para que quem augura ser membro ativo da sociedade da informação e do conhecimento se conscientize de que terá de adotar, também na escrita, o registo ajustado às variadas situações com que vier a confrontar-se.

Intenta-se assim indicar a quem necessite de escrever trabalhos académicos, nomeadamente artigos científicos, alguns pontos norteadores que são à primeira vista banais para quem estiver muito habituado a redigi-los, mas que o serão talvez em menor escala para os que se iniciam nesta faceta de uma habilidade, a escrita, tão rica em termos de aprendizagem e tão promissora a longo prazo do ponto de vista cognitivo.

Na realidade, conforme lembra Emig (1977), a escrita será o processo verbal que mais contribui para a aprendizagem porque concilia nela o contributo da vertente cognitiva, através do cérebro, da vertente sensorial, por meio da visão, e da vertente motora, através da mão. Sabe-se bem como a memória revela uma abertura especial a tudo o que provenha de diferentes frentes. Por outro lado, não surpreende que uma prática continuada de uma tarefa que implique mais recursos cognitivos, sensoriais e motores possa representar um baluarte contra o declínio que o avançar da idade pode acarretar. 
Linha D'Água (Online), São Paulo, v. 31, n. 1, p. 9-27, jan.-abril 2018

\section{A escrita académica e o que a distingue de práticas de escrita anteriores}

Que terá de diferente a escrita académica exigida no ensino superior da escrita praticada até essa altura?

Uma possível e rápida resposta irá na direção de indicar o tipo de leitura que se deve solicitar aos estudantes que tenham de escrever um trabalho académico. Deles se requer que leiam com atenção e de modo crítico os materiais que lhes são fornecidos ou aconselhados para as temáticas em estudo. Essa leitura não deve, porém, estar unicamente focada no conteúdo; ela terá de atender também à forma, algo para o qual o processamento descendente, de uso mais frequente no ato de ler nessas idades, não se apresentará como o mais facilitador. Os estudantes têm, naturalmente, de se concentrar no sentido, mas também têm de reparar no modo como este é veiculado, conjugando o processamento ascendente com o descendente sempre que a leitura das matérias a isso obrigue. Conforme adverte Nwogu (1997), os trabalhos académicos, mais particularmente os artigos científicos, têm de ser redigidos de molde a que o leitor sinta que neles foi respeitada uma organização do conteúdo que se distribui por diferentes passos do seu articulado. Será, então, essa articulação dos conteúdos que não pode deixar de ser tida em consideração pelos estudantes, sempre que leem artigos científicos, para que a possam seguir quando pretenderem transmitir capazmente a informação que desejam que atinja o público leitor. Acrescenta o autor citado que a ausência dessa conscientização "may account partly for the difficulty which most writers, especially new entrants into the academic discourse community face with producing clear, coherent and logically organized research reports" (NWOGU, 1997, p. 119).

Se até à entrada no ensino superior a tónica pode ter recaído essencialmente numa abordagem mais virada para a apreensão da matéria sem grandes distâncias críticas, a Universidade terá de fazer sentir sem equívocos que a ênfase tem de passar a incidir na análise da informação assente num pensamento crítico (MURRAY, 2012). Interessa criar esse espírito crítico, porquanto, vencida essa fase, este pode transpor-se facilmente e com todos os benefícios para outros domínios que também reclamem essa atitude crítica e analítica, imprescindível à subsequente síntese inovadora. 
Linha D'Água (Online), São Paulo, v. 31, n. 1, p. 9-27, jan.-abril 2018

Todo o olhar crítico acerca de qualquer temática e tudo o que se vier a investir num trabalho académico para que resulte original e contenha a voz do seu autor demandam uma boa preparação no plano da informação sobre o assunto a ser tratado. Parte desse trabalho decorre do conhecimento do que em relação ao assunto foi dito, mas principalmente do que a seu respeito foi escrito. Qualquer autor terá, por conseguinte, de fazer uma investigação cuidada a respeito do tema a tratar valendo-se de diferentes fontes, a fim de, a partir da conjugação de perspetivas relativas ao tópico que elegeu para estudo, poder derivar a sua interpretação criativa, com a ajuda, sendo caso disso, dos resultados que possa ter obtido se o seu trabalho contiver uma parte empírica.

O ensino, a forma como o professor se posiciona para preparar o estudante com vista à obtenção dos resultados esperados em trabalhos académicos, é deveras crucial. Se o ensino não se revela adequado ou não segue o rumo devido, não será impossível dar-se razão a Odell quando faz pensar que há algo que falha no sistema quando a escrita dos estudantes é pobre ou não corresponde aos níveis desejados.

Para mostrar como é relevante a aproximação dos estudantes à bibliografia para que dela procedam textos com originalidade e nos quais esteja presente a voz de quem redige, afigura-se oportuno transcrever parte do testemunho de uma estudante de um seminário de mestrado que espelha o que sentiu relativamente ao seu processo de aprendizagem:

No que me diz respeito, [...], fui confrontada com muitos textos e, claro, com vários textos de diferentes autores com conceitos diferentes e apoiando-se em várias áreas de estudo sobre o mesmo tema.

Se digo confrontada é porque a atitude de leitura desses vários textos sobre o mesmo tema, me obrigou a vários níveis de confronto. $\mathrm{O}$ primeiro de mim com cada um dos textos separadamente; o segundo com os vários textos perante o mesmo tema, ou seja, o que os distingue e o que os associa; o terceiro nível de confronto, de novo o de mim própria com a síntese comparativa obtida e a minha opinião pessoal.

O estudo comparativo, e finalmente sintetizado, resultou de um trabalho reflexivo sobre a linguagem escrita. E, por sua vez, esse estudo refletir-se-á, num trabalho escrito pelo recetor, trabalho que deverá usar algum termo técnico ou definição 
Linha D'Água (Online), São Paulo, v. 31, n. 1, p. 9-27, jan.-abril 2018

de conceito retirados dos textos estudados. Dir-se-á que a linguagem usada "copia" o que encontrou.

Mas no trabalho de síntese referido como último nível, o recetor usará a sua linguagem própria matizada com o que de fundamental pensou retirar dos textos. Já não é a linguagem copiada, mas a linguagem refletida.

Ora, este tipo de trabalho universitário permite não só o acréscimo do saber, pela leitura, daquele que estuda, mas também (e igualmente importante) adquirir a consciência da relação de posições do saber e da vocação "universal" que compete à própria Universidade fomentar.

Neste trecho, vê-se com uma clareza pouco comum a importância de saber ensinar a ler quem está a aprender a escrever trabalhos académicos. Num cenário como este, o jogo entre a leitura e a escrita está efetivamente muito presente e compete, sem dúvida, ao professor preparar a atmosfera propícia a essa conjugação.

Do fragmento transcrito, sobressai todo o labor multicognitivo operado pela relatora face aos textos que estudou para, por fim, do diálogo entabulado com os mesmos fazer ressaltar a sua própria voz. Documenta-se o mencionado labor multicognitivo, tomando este último termo de empréstimo a Odisho (2007), com algumas expressões usadas pela autora do testemunho: "confronto", "distinguir", "associar”, "síntese comparativa”, "trabalho reflexivo", "linguagem copiada", "linguagem refletida".

São depoimentos desta qualidade que motivam quem ensina e que contribuem para desvelar o que acontece na arena da cognição aquando da operacionalização que a escrita reivindica. Saber o que se desenrola nessa arena não é empresa fácil, posto que nem todos conseguem dar um retrato fiel do que estão a vivenciar. $\mathrm{Na}$ citação em foco, a estudante soube contar o que estava a suceder na sua arena da cognição e partilhou essa experiência como poucos o fariam. Justo será dizer que todos saem a lucrar de relatos como este e seria bom que ele servisse de exemplo aos estudantes que ainda não conseguiram chegar a este patamar, quer no atinente ao modo de atuar que deles é esperado, quer no que tange à consciencialização do esforço cognitivo que deles reclama a elaboração de um trabalho académico.

Depreende-se do trecho reproduzido que não é empreendimento fácil atingir a esperada originalidade de um texto académico que não se consubstância, em nenhuma circunstância, sem uma investigação que lhe faculte a sustentação 
Linha D'Água (Online), São Paulo, v. 31, n. 1, p. 9-27, jan.-abril 2018

teórica necessária. Não será mesmo de excluir a menção, como se pode ler em Pinto (2016), de outros tantos conceitos que andam associados à originalidade: autoria (PENROSE; GEISLER, 1994. STARFIELD, 2002), identidade (HIRVELA; BELCHER, 2001, ABASI; AKBARI; GRAVES, 2006), voz (PRIOR, 2001, WINGATE, 2012), posição (STREET, 2009), atribuição (HYLAND, 1999, JALILIFAR; CHAMRAN, 2012, MASTURA; AZLAN, 2013), citação (SWALES, 1990, JAKOBS, 2003, PETRIĆ, 2007, MACEDO; PAGANO, 2011, PETRIĆ, 2012), paráfrase (KECK, 2006), intertextualidade transgressiva (CHANDRASOMA; THOMPSON; PENNYCOOK, 2004), plágio (HOWARD, 1993, 1995, PECORARI, 2003) e "patchwriting" (HOWARD, 1995, PECORARI, 2006).

A integridade de um trabalho académico vive de uma congregação de atitudes perante a escrita que devem necessariamente confluir num todo em que todos os conceitos enumerados são objeto da merecida ponderação.

Ninguém nasce programado para, logo à primeira tentativa, redigir trabalhos académicos que sejam publicados imediatamente sem quaisquer recomendações. Para se alcançar esse estágio, todo um percurso tem de ser calcorreado e, quase sempre, com muita perseverança. Não será sem experiência de causa que D. Murray (2013, p. 1) escreve: "First emptiness, then terror, at last one word, then a few words, a paragraph, a page, finally a draft that can be revised".

Quantos estudantes, para que o leitor/professor não pense que estão a plagiar, consideram que basta colocar entre parênteses, após cada passagem que reproduzem quase na íntegra, o nome do autor, o ano e, por vezes, mesmo a página, embora esta última só seja necessária no caso das citações ipsis verbis que têm de surgir sempre entre aspas. A atribuição que é feita é por certo obrigatória, a menção, que corresponde, na ocorrência, a uma referência não integrada da literatura trabalhada, também é digna de alguma compreensão; sem embargo, a autoria de quem está a redigir o texto, a sua identidade, a sua voz e a sua posição diluem-se, se é que se encontram de algum modo latentes, porque falta a quem escreveu a capacidade de interpretar as leituras feitas tirando partido do labor multicognitivo aduzido no testemunho transcrito. 
Linha D'Água (Online), São Paulo, v. 31, n. 1, p. 9-27, jan.-abril 2018

Muito se terá de fazer junto dos estudantes para que aprendam a parafrasear sem transgredir e para que se distanciem do "patchwriting", que, em vez de ser motivo de penalização, deveria assumir o papel de oportunidade pedagógica (HOWARD, 1995).

A escrita como prática conhece etapas e a da "manta de retalhos", a do "patchwriting", feita de transcrições de ideias e palavras de autores referidos de modo não integrado, como se de uma anotação se tratasse, terá de ser compreendida como um momento preliminar do trajeto de escrita que qualquer estudante deve experienciar.

No plano do que se poderá considerar o conhecimento de escrita-composição que um estudante de graduação deve possuir, cumpre destacar: 1) que é de todo o interesse que dê por palavras suas o que sentiu de utilidade para fundamentar as ideias que quer defender, fugindo assim ao "patchwriting"; 2) que saiba alternar as referências à literatura não-integradas, cujo enfoque se localiza na informação, com as integradas, que fazem recair a tónica sobre o autor dessa informação, procurando modalizar a função na frase das autoridades que vão conferir credibilidade ao texto e assim evitar o uso continuado de formulações como: "segundo x", "de acordo com x", "para x"; 3) que sinta onde se situa o melhor momento para inserir uma citação, que terá de ser bem incorporada, tendo em vista o cotexto, bem introduzida, no que se reporta ao contexto, estar entre aspas e apresentar-se acompanhada da página da obra de onde foi extraída, uma vez que só assim qualquer trabalho académico resulta num todo coeso e aceitável cientificamente; 4) que se perceba que uma citação serve para fundamentar um dado pensamento e, como tal, deve ser aplicada de um modo cirúrgico e não abusivamente; 5) que, salvo raras exceções bem assinaladas, deve evitar referências à literatura não acedidas diretamente, ou seja, secundárias, indiretas, porquanto nunca se sabe se os mediadores oferecem delas a leitura mais correta; 6) que faça sair a sua voz de uma formulação em que a primeira pessoa do singular não figure, porque tal só se consente a autores já conceituados no mundo da ciência e não a iniciantes.

\section{A estrutura de um trabalho académico com parte empírica}

Atendendo a que um trabalho académico não deve conter imperfeições, houve até o momento a preocupação de deixar alguns conselhos relacionados com aspetos 
Linha D'Água (Online), São Paulo, v. 31, n. 1, p. 9-27, jan.-abril 2018

ligados essencialmente à redação. Chegada é a altura de abordar a estrutura de um género textual que contemple também uma parte empírica. Trabalhos com partes empíricas têm vindo a ser cada vez mais adotados em áreas que nos são também familiares dado que se tem verificado um interesse crescente por vertentes aplicadas nessas áreas e se tem igualmente sentido que a aplicação é vista pelos estudantes com agrado. A estrutura que servirá de modelo nas nossas áreas segue, como não poderia deixar de ser, o que foi consagrado antes por outras áreas do saber (SOLLACI; PEREIRA, 2004).

Assume alguma relevância, mormente para quem se inicia na escrita científica, alertar para a existência, dependendo das atividades exercidas, de diferentes modos de ler um texto académico, razão pela qual a estrutura final deste não espelha obrigatoriamente o percurso de quem o realizou. Um cientista, um editor ou um avaliador não lerão certamente um artigo científico seguindo de igual modo a ordem prescrita pela comunidade científica para o seu formato. Os editores e os avaliadores, como nota Burrough-Boenisch (1999), porque leem o artigo antes de ser publicado, tudo fazem para que este venha a ser uma publicação aceita pela comunidade científica. Deve, por isso, ostentar uma configuração adequada à informação a difundir; quanto aos cientistas, visto que têm acesso ao produto acabado, não precisam de sacrificar a sua leitura à ordem de ocorrência dos dados no artigo. Leem, assim, como entenderem e em conformidade com os seus objetivos, saltando no artigo de secção para secção, na busca do que lhes interessa naquele momento. Sollaci e Pereira (2004: 366) observam inclusivamente que a organização dos artigos "may be largely credited to editors, who insisted on papers being clearly formatted to benefit readers and to facilitate the process of peer review". Ainda no que concerne à organização/formatação dos artigos, Burrough-Boenisch (1999, p. 298) assinala que "it forces scientists to write and think in a certain paradigm that is not a true reflection of the process of scientific investigation", observação que corrobora o que se avançou antes a propósito da possível discrepância entre a forma como o trabalho do cientista é projetado e a sua posterior passagem a versão escrita. Essa discrepância advém do facto de quem escreve um artigo ter de seguir regras aquando da sua publicação. A apresentação dos conteúdos que integram o artigo está, portanto, sujeita a uma narrativa multi-modal (VIHLA, 1999) que 
Linha D'Água (Online), São Paulo, v. 31, n. 1, p. 9-27, jan.-abril 2018

serve de linha condutora tanto para o autor como para o leitor (MIŚAK; MARUŚIĆ; MARUŚIĆ, 2005).

A formatação aludida e que mais se compagina com a mencionada narrativa multi-modal, que sucedeu, pelo menos nas ciências da saúde, a uma escrita inicialmente descritiva (SOLLACI; PEREIRA, 2004), corresponde à estrutura Introdução, Métodos, Resultados e Discussão (IMRD), às vezes referida como IMRAD ou IMRaD, representando o A/a o "and" da língua inglesa. Esta estrutura, independentemente da sua denominação, começou a impor-se durante o século XX. Seguindo a mesma fonte, ela ganha forma em 1950, aumentando a sua implementação em 1970 e tornando-se comum nos anos 80 do século pretérito. De resto, Sollaci e Pereira (2004) adiantam que este formato viria a ser o recomendado pelas conferências internacionais a partir da Segunda Guerra Mundial. Para as revistas da área da Medicina, foram publicadas as primeiras normas em 1979 pelo "Vancouver Group", que viria a originar o "International Committee of Medical Journal Editors” (ICMJE) (1997).

Acresce-se, com base na "Academy of Social Sciences and Humanities", que, em áreas que nos são mais próximas e que também recorrem a partes empíricas, a estrutura IMRAD também começou a ser recomendada para os respetivos trabalhos científicos pela "American Psychological Association". ${ }^{1}$

Das quatro secções da estrutura IMRD, Alexandrov (2004: 136) aponta como mais relevante a dos Resultados. Esta secção leva Miśak, Maruśić e Maruśić (2005) a afirmarem que "is the most original part of the study and presents the most valid and important findings of the study" (p. 127). Note-se que, nessa parte original do estudo, estes autores integram igualmente os Métodos. Libra (2001), por sua vez, destaca os Resultados e a Discussão como as secções mais importantes do trabalho académico. Essa posição não surpreende, dado o papel que assume, em termos de mais-valia e de desafio, o diálogo que deve registar-se na Discussão entre os resultados obtidos e o que outros autores já divulgaram - matéria constante da Introdução -, permitindo dar lugar à "verdade interpretada” aduzida por Skelton (1997).

1 Disponível em https://arjiptai.wordpress.com/2011/07/17/imrad/. Acesso em 19 jan. 2016.

PINTO, M. G. L. C. Os meandros da escrita académica. Alguns recados aos estudantes universitários 
Linha D'Água (Online), São Paulo, v. 31, n. 1, p. 9-27, jan.-abril 2018

Se as secções Métodos e Resultados forem tidas como as mais originais e imprescindíveis num estudo com componente empírica, espera-se que a Introdução funcione como um funil (LIBRA, 2001), como um triângulo invertido (MIŚAK; MARUŚIĆ; MARUŚIĆ, 2005), que de forma concisa, isto é, sem divagações, conduza o autor para o problema que quer resolver, com a necessária fundamentação bibliográfica, para os objetivos (geral e específicos) do trabalho em causa, para a hipótese que quer validar e, ao mesmo tempo, para a questão ou questões metodológicas a que o seu estudo visa dar resposta. A Discussão, por seu lado, vive dos resultados obtidos. A partir deles, o autor tenta salientar os pontos fortes do seu estudo e também apontar, com a precaução necessária, para as ilações a retirar dos resultados encontrados, socorrendo-se do material verbal ajustado às circunstâncias, nomeadamente de atenuadores, para não arriscar demasiado (HYLAND, 1994, PINTO; OSÓRIO; MARTINS, 2014). Esta secção integra frequentemente notas conclusivas, posto que o leitor aguarda uma súmula dos resultados, que devem ser comparados e confrontados com os já existentes, bem como um comentário acerca das limitações que sempre existem em trabalhos deste cariz e ainda a listagem de algumas questões que possam vir a ser tratadas em estudos futuros (MURRAY, 2012).

Regressando aos Métodos e Resultados, as que supostamente têm de oferecer à comunidade científica algo de novo, convém, na linha de Miśak, Maruśić e Maruśić, (2005), avançar que a secção Métodos "is the easiest part to write, as it describes what was done and in what order” (p. 125). É, efetivamente, a secção que, como consta do documento da "Academy of Social Sciences and Humanities" (ver nota 1 deste texto), deve responder às perguntas: "when, where, and how was the study done? What materials were used or who was included in the study groups [...]?"

Quanto à primeira parte da citação de Miśak, Maruśić e Maruśić, em que a secção Métodos é considerada a parte mais fácil de escrever de um trabalho, essa passagem pode ser um bom recado para quem está a iniciar na escrita de textos académicos.

Já as perguntas indiretas e diretas constantes das citações feitas carecem de respostas completas, porque só através delas os estudos publicados podem ser replicados. A secção Métodos funciona como se fosse uma receita de culinária, comparação que se encontra, de resto, em textos destinados a ensinar como escrever um trabalho 
Linha D'Água (Online), São Paulo, v. 31, n. 1, p. 9-27, jan.-abril 2018

académico com parte empírica (LIBRA, 2001). O desenho do estudo deve, por isso, conter uma boa descrição nas suas diversas partes (participantes, materiais, métodos, instrumentos estatísticos, entre outros). Relativamente à estatística, atente-se na seguinte passagem das recomendações do ICMJE (1997): "Describe statistical methods with enough detail to enable a knowledgeable reader with access to the original data to judge its appropriateness for the study and to verify the reported results". Nas mesmas recomendações, ainda a respeito da estatística, também se lê que deve ser evitada a referência unicamente a valores de $P$ porque se perde informação acerca do "effect size" e da "precision of estimates" (p. 14). ${ }^{2}$

Da secção Resultados, por seu turno, esperam-se respostas a perguntas como as constantes no documento da "Academy of Social Sciences and Humanities": "what answer was found to the research question; what did the study find? Was the tested hypothesis true?" (ver nota 1 deste texto). A propósito desta secção, realçam-se ainda os seguintes pontos que ocorrem nas recomendações da ICMJE (1997, p. 14-15) (ver nota 2 deste texto): apresentação dos resultados numa ordem decrescente de relevância seguindo uma ordem lógica no texto, tabelas e figuras; a não ocorrência de informação repetida no texto e nas representações gráficas, bem como a sua não duplicação nas mesmas; a não referência só a percentagens, dada a utilidade da presença dos números absolutos de onde provêm os valores calculados. Para concluir, as observações respeitantes à secção em apreço, vale a pena citar Alexandrov (2004, p. 136): "Make data presentation so clear and simple that a tired person riding late on an airplane can take your manuscript and get the message at first reading”. Esta citação tanto apela para uma boa exposição dos resultados como para a forma como se processa a leitura de um artigo científico. Se a secção Resultados pode ser considerada a mais relevante por cativar preferentemente o público interessado nestes estudos, então a forma como são difundidos os dados assume um papel fulcral.

Em matéria de trabalhos académicos, o título e as referências têm de ser inevitavelmente convocados. $\mathrm{O}$ resumo e as palavras-chave não parecem necessitar de grandes tratamentos, uma vez que o resumo não exige mais que uma retomada, num

2 Disponível em: http://www.icmje.org/icmje-recommendations.pdf. Acesso em 19 jan. 2016.

PINTO, M. G. L. C. Os meandros da escrita académica. Alguns recados aos estudantes universitários 
Linha D'Água (Online), São Paulo, v. 31, n. 1, p. 9-27, jan.-abril 2018

número prescrito de palavras, do conteúdo do artigo e as palavras-chave reproduzem, num número também estabelecido, os pontos-chave do trabalho desenvolvido.

O título, esse, sim, merece alguma atenção. Tem mesmo todo o cabimento citar as palavras de Alexandrov (2004, p. 135): "The title sells the paper." Na verdade, um título pode ser ou não motivador da leitura de um artigo, o que lhe incute grande responsabilidade. Pode ser mais ou menos longo, de acordo com as áreas de saber, deve conter as variáveis esperadas, de índole dependente e independente, que foram trabalhadas no estudo que encabeça, e pode consistir quer num único constituinte, quer em dois, surgindo o segundo - o subtítulo - precedido com frequência de dois pontos. O título deve, pois, chamar a si o que de importante o autor quis comunicar no seu texto. Dessa forma, com maior ou menor infalibilidade, funcionará como motor da leitura do texto que introduz (ver, em torno dos títulos, BAICCHI, 2003, HAGGAN, 2004, LEWISON; HARTLEY, 2005, HARTLEY, 2007).

As referências são também uma parte indispensável dos artigos/trabalhos científicos porque, além de outros aspetos, não é raro encontrar leitores que as elegem como pontos de entrada nesses textos. Para que a sua transcrição seja rigorosa, têm de surgir de modo completo, respeitando normas previamente estabelecidas e seguindo a ordem alfabética. Ademais, nos artigos/trabalhos visados, as referências finais devem impreterivelmente cobrir todos os autores deles constantes, que, por seu lado, têm também de nelas estar presentes, gerando-se assim uma relação biunívoca.

\section{Nota final}

Conquanto a temática a ser tratada possa estar já bem definida, o rumo a que a escrita impele pode ser uma surpresa. Esse é o retrato da escrita como aventura, no que ela tem afinal de criativo, mesmo que não se trate da escrita ficcional. D. Murray (2013, p. 28), de uma forma seminal, ecoa essa faceta desta atividade/habilidade ímpar quando escreve: "the writing comes in the writing". Não se trata, aliás, de nenhuma novidade para quem sabe o que significa redigir um texto. Talvez sirva, no entanto, de ensinamento, de recado, para quem ainda não pratica a escrita com a sistematicidade desejada. 
Linha D'Água (Online), São Paulo, v. 31 , n. 1, p. 9-27, jan.-abril 2018

A escrita deve ser vista como uma prática e é assim que se estima que os estudantes a tomem, sem que se deixem vencer seja pela inércia, seja por qualquer outra força inibitória que a tarefa de composição lhes possa incutir.

Este texto não é prescritivo. Não se pode esperar dele uma receita. Ele visa, essencialmente, dar a entender o que de relevante constitui uma leitura crítica da pesquisa bibliográfica que a escrita subordinada a um dado tópico demanda. Objetiva, ainda, levar a operar multicognitivamente as fontes consultadas para que a interpretação daí resultante origine um texto com voz própria e consequentemente único. A singularidade desse texto advirá de não existirem duas pessoas que possuam idênticos conhecimentos prévios e que leiam e compreendam, sob a mesma perspetiva, a bibliografia que serve de base ao texto a executar. Espera-se, por isso, que os estudantes estejam atentos tanto ao conteúdo como à estrutura dos textos consultados. As fontes poderão então ser também usadas como inspiração a fim de que aprendam a organizar os seus próprios textos por analogia.

No fundo, os procedimentos conducentes à aprendizagem são diversificados. Quem quer realmente aprender só precisa de estar recetivo a novas conquistas e, acima de tudo, atento às múltiplas vias de ensino existentes. As instituições educativas serão seguramente uma dessas vias, mas muitas mais existirão. Resta a cada estudante saber tirar partido de toda a oferta existente e interiorizar que a escrita, para além de um trabalho, de uma arte, é também um investimento para a vida, levando em conta, entre outros, os seus efeitos de ordem cognitiva a longo prazo.

\section{Referências}

ABASI, Ali R.; AKBARI, Nahal.; GRAVES, Barbara. Discourse appropriation of identities, and the complex issue of plagiarism: ESL students writing in graduate school. Journal of Second Language Writing, v. 15, p. 102-117, 2006.

ALEXANDROV, Andrei V. How to write a research paper. Cerebrovascular Diseases, v. 18, p. 135-138, 2004. 
Linha D'Água (Online), São Paulo, v. 31, n. 1, p. 9-27, jan.-abril 2018

BAICCHI, Annalisa. Relation complexity of titles and texts: a semiotic taxonomy. In: BARBARESI, Lavinia Merlini. (Ed.) Complexity in language and text. Università di Pisa: Edizione PLUS, 2003, p. 319-341,

BALLE, Francis. Pour comprendre les média. Mac Luhan. Analyse critique. Profil d'une Oeuvre. Collection dirigée par Georges Décote. Sciences Humaines. Paris: Hatier, 1972.

BURROUGH-BOENISCH, Joy. International reading strategies for IMRD articles. Written Communication, v. 16, n. 3, p. 296-316, 1999.

CHANDRASOMA, Ranamukalage;THOMPSON, Celia; PENNYCOOK, Alastair. Beyond plagiarism: Transgressive and nontransgressive intertextuality. Journal of Language, Identity, and Education, v. 3, n. 3, p. 171-193, 2004.

CRYSTAL, David. Language and the internet. Cambridge: Cambridge University Press, 2001.

EMIG, Janet. Writing as a mode of learning. College Composition and Communication, v. 28, n. 2, p. 122-128, 1977.

HAGGAN, Madeline. Research paper titles in literature, linguistics and science: dimensions of attraction. Journal of Pragmatics, v. 36, p. 293-317, 2004.

HARTLEY, James. Planning that title: Practices and preferences for titles with colons in academic articles. Library E' Information Science Research, v. 29, p. 553-568, 2007.

HIRVELA, Alan; BELCHER, Diane. Coming back to voice. The multiple voices and identities of mature multilingual writers. Journal of Second Language Writing, v. 10, p. 83-106, 2001.

HOWARD, Rebecca Moore. A plagiarism pentimento. Journal of Teaching Writing, v. 11, n. 3, p. 233- 245, 1993.

Plagiarisms, authorships, and the academic death penalty. College English, v. 57, n. 7, p. 788-806, 1995.

HYLAND, Ken. Hedging in Academic Writing and EAP Textbooks. English for Specific Purposes, v. 13, n.3, p. 293-256, 1994.

PINTO, M. G. L. C. Os meandros da escrita académica. Alguns recados aos estudantes universitários 
Linha D'Água (Online), São Paulo, v. 31, n. 1, p. 9-27, jan.-abril 2018

Academic attribution: Citation and the construction of disciplinary knowledge. Applied Linguistics, v. 20, n.3, p. 341-367, 1999.

ICMJE (International Committee of Medical Journal Editors. Uniform requirements for manuscripts submitted to biomedical journals). Annals of Internal Medicine. Jan1, v. 126, n. 1, p. 36-47, 1997.

JAKOBS, Eva-Maria. Reproductive writing - writing from sources. Journal of Pragmatics, v. 35, p. 893-906, 2003.

JALILIFAR, Alireza; CHAMRAN, Shahid. Academic attribution: Citation analysis in master's theses and research articles in applied linguistics. International Journal of Applied Linguistics, v. 22 , n. 1, p. 23-41, 2012.

KECK, Casey. The use of paraphrase in summary writing: A comparison of L1 and L2 writers. Journal of Second Language Writing, v. 15, p. 261-278, 2006.

LEWISON, Grant; HARTLEY, James. What's in a title? Number of words and the presence of colons. Scientometrics, v. 63, n. 2, p. 341-356, 2005.

LIBRA, Judy A. How to Write a Paper. Introduction to Scientific Work Seminar, Module 6. International Study Course Environmental and Resource Management, Brandenburg Technical University Cottbus, Germany, 2001.

MACEDO, Tatiana S. de; PAGANO, Adriana Silvina. Análise de citações em textos acadêmicos escritos. Revista D.E.L.T.A, v. 27, n. 2, p. 257-288, 2011.

MASTURA, Nik; AZLAN, Nik Ismail. Citation typologies and rhetorical functions of citations in master dissertations. Creative Practices in Language Learning and Teaching, v. 1, n. 2, p. 61- 74, 2013. Disponível em: http://www.kedah.uitm.edu.my/CPLT/images/stories/v1n2/ Article5.pdf. Acesso em: 6-08-2015.

MIŚAK, Aleksandra; MARUŚIĆ, Matko; MARUŚIĆ, Ana. Manuscript editing as a way of teaching academic writing: Experience from a small scientific journal. Journal of Second Language Writing, v. 14, p. 122-131, 2005.

MURRAY, Donald M. The craft of revision. Fifth Anniversary Edition. United States: Wadsworth Cengage Learning, 2013.

PINTO, M. G. L. C. Os meandros da escrita académica. Alguns recados aos estudantes universitários 
Linha D'Água (Online), São Paulo, v. 31, n. 1, p. 9-27, jan.-abril 2018

MURRAY, Neil. Writing essays in English language and linguistics. Principles, tips and strategies for undergraduates. Cambridge: Cambridge University Press, 2012.

NWOGU, Kevin Ngozi. The medical research paper: Structure and functions. English for Specific Purposes, v. 16, n. 2, p. 119-138, 1997.

ODELL, Lee. Teaching writing by teaching the process of discovery: an interdisciplinary enterprise. In: GREGG, Lee W.; STEINBERG, Erwin R. (Eds.). Cognitive processes in writing. Hillsdale, New Jersey: Lawrence Erlbaum Associates, Publishers, 1980, p. 139-154.

ODISHO, Edward Y. A Multisensory, multicognitive approach to teaching pronunciation. Linguística - Revista de Estudos Linguísticos da Universidade do Porto, v. 2, p. 3-28, 2007.

PECORARI, Diane. Good and original: Plagiarism and patchwriting in academic second-language writing. Journal of Second Language Writing, v. 12, p. 317-345, 2003.

Visible and occluded citation features in postgraduate second-language writing. English for Specific Purposes, v. 25, p. 4-29, 2006.

PENROSE, Ann. M.; GEISLER, Cheryl. Reading and wrting without authority. College Composition and Communication, v. 45, n. 4, p. 505-520, 1994.

PETRIĆ, Bojana. Rhetorical functions of citations in high- and low-rated master's theses. Journal of English for Academic Purposes, v. 6, p. 238-253, 2007.

Legitimate textual borrowing: Direct quotation in L2 student writing. Journal of Second Language Writing, v. 21, p. 102-117, 2012.

PINTO, Maria da Graça Lisboa Castro. A escrita académica: um jogo de forças entre a geração de ideias e a sua concretização. Signo. Santa Cruz do Sul, v. 41, n. esp., p. 53-71, jan./jun. 2016.

PINTO, Maria da Graça; OSÓRIO, Paulo; MARTINS, Fernanda. A theoretical contribution to tackling certainty and uncertainty in scientific writing: four research articles from the journal Brain in focus. In: ZUCZKOWSKI, Andrzej; BONGELLI, Ramona; RICCIONI, Ilaria; CANESTRARI, Carla. (Eds.). Communicating Certainty and Uncertainty in Medical, Supportive and Scientific Contexts. Amsterdam: John Benjamins Publishing Company, 2014, p. 291-308.

PINTO, M. G. L. C. Os meandros da escrita académica. Alguns recados aos estudantes universitários 
Linha D'Água (Online), São Paulo, v. 31, n. 1, p. 9-27, jan.-abril 2018

PRIOR, Paul. Voices in text, mind, and society. Sociohistoric accounts of discourse acquisition and use. Journal of Second Language Writing, v. 10, p. 55-81, 2001.

SKELTON, John. The representation of truth in academic writing. Applied Linguistics, v. 18, n. 2, p. 121-140, 1997.

SOLLACI, Luciana B.; PEREIRA, Maurício Gomes. The introduction, methods, results, and discussion (IMRAD) structure: a fifty-year survey.J Med Libr Assoc., v. 92, n. 3, p. 364-367, 2004.

STARFIELD, Sue. "I'm a second-language English speaker": Negotiating writer identity and authority in sociology one. Journal of Language, Identity, and Education, v. 1, n. 2, p. 121-140, 2002.

STREET, Brian. "Hidden" features of academic paper writing. Working papers in Educational Linguistics, v. 24, n. 1, p. 1-17, 2009.

SWALES, John. M. Genre analysis: English in academic and research settings. $13^{\text {th }}$ printing 2008. Cambridge: Cambridge University Press, 1990.

VIHLA, Minna. Medical Writing. Modality in Focus. Amsterdam - Atlanta, GA: Editions Rodopi B.V., 1999.

WINGATE, Ursula. 'Argument!' helping students understand what essay writing is about. Journal of English for Academic Purposes, v. 11, p. 145-154, 2012.

Recebido em 07/01/2018.

Aprovado em 22/02/2018. 